\title{
Evaluation of Invasive Intra-abdominal Candidiasis in Crohn Disease at the Time of Surgery
}

\author{
Martin Šašala ${ }^{1,2}$, Emeše Majorová $^{3,4}$, Andrej Vrzgula ${ }^{1,2}$, Iveta Fandáková ${ }^{5}$ \\ ${ }^{1}$ Surgery Department, Faculty of Medicine, P.J. Šafárik University, Košice; ${ }^{2}$ Hospital Košice-Šaca, Ltd., 1st Private Hospital, Košice-Šaca; \\ ${ }^{3}$ Department of Paediatric and Adolescent Medicine, Children’s University Hospital, Faculty of Medicine, P.J. Šafárik University, Košice; \\ ${ }^{4}$ Gastroenterology Outpatient Ambulatory, ERGOMED, Ltd., Košice; ${ }^{5}$ Clinical Microbiology, Synlab Slovakia, Ltd., Košice, Slovakia
}

Purpose: The aim of this study was to determine whether a connection exists between Crohn disease and fungi, specifically Candida albicans, because one possible cause of disease is thought to be the presence of fungi in the intra-abdominal cavity. The diagnosis of invasive candidiasis is difficult due to the lack of specific clinical manifestations of the disease. A retrospective evaluation of the presence of invasive candidiasis was done in a group of 54 patients with Crohn disease and in a group of 31 patients who received surgery primarily for right-sided cancer of the colon.

Methods: Culture samples were obtained from the wall of the extraluminal portion of the terminal ileum and the adjacent mesenterium, and then sent to the microbiology laboratory for further investigation. Sabouraud agar (SGC2) and chromID Candida agar (CAN2) were used for both short-term (48 hours) and long-term (10 days) cultivation.

Results: Pearson chi-square test revealed a statistically significant difference in the prevalence of fungi and yeast between the 2 groups of patients $\left(\chi^{2}=4.3873, \mathrm{P}<0.05\right)$.

Conclusion: Patients with Crohn disease had a significantly higher prevalence of fungi and yeasts in the intra-abdominal cavity compared with cancer patients.

Keywords: Surgery; Crohn disease; Candidiasis

\section{INTRODUCTION}

The exact origin of Crohn disease (CD) and colitis ulcerosa is unknown, but it is widely accepted that the characteristic inflammation in CD, a type of inflammatory bowel disease (IBD), is the result of dysregulated immune interactions between the host and components of the intestinal microbial flora. Many attempts have been made to identify common and uncommon organisms of bacterial, viral, or fungal origin responsible for these diseases. However, valid and reproducible scientific evidence on the identi-

Received: August 4, 2018 - Accepted: October 15, 2018

Correspondence to: Martin Šašala, M.D.

Surgery Department LF UPJŠ, 1st Private Hospital Košice-Šaca, Ltd., Lúčna

57, 04015 Košice-Šaca, Slovakia

Tel: +421903122855, Fax: +421557234444

E-mail:marsasala@hotmail.com

ORCID: https://orcid.org/0000-0002-0562-1362

(C) 2020 The Korean Society of Coloproctology

This is an open-access article distributed under the terms of the Creative Commons Attribution NonCommercial License (https://creativecommons.org/licenses/by-nc/4.0) which permits unrestricted noncommercial use, distribution, and reproduction in any medium, provided the original work is properly cited. fication and confirmation of the most likely candidates is still lacking. Some studies have shown that Candida colonization is associated with several diseases of the gastrointestinal tract [1-3]. Although the relationship between fungi and CD has not been clearly established, there is some evidence for the possible role of Candida albicans in the processes leading to or maintaining inflammation. In numerous patients, the yeast spreads from the gastrointestinal tract to other organs, which explains why a Candida bloodstream infection can lead to devastating disease [4]. $\mathrm{CD}$ is chiefly managed using nonoperative treatment. Upon failure of medical management or the development of complications, surgery should be considered [5]. The aim of our study was to evaluate the occurrence of $C$. albicans in the intra-abdominal cavity of patients considered for surgery due to a failure of conservative or immunosuppressive treatment. Although surgery was planned for these patients, they were not in the acute stage of the disease. Patients with an intra-abdominal abscess, neutropenia, or fever were excluded from the study, and patients with right-sided colon cancer were used as a control group. 


\section{METHODS}

We conducted a retrospective cohort study of consecutive cases of CD admitted to the surgery department of our hospital during 2014-2017. There were 54 patients ( 34 males and 20 females) with a mean age of 35.4 years (range, $18-57$ years) (Table 1). All patients were monitored by a gastroenterologist and were recommended for surgery due to a failure of conservative treatment and the occurrence of complications. The duration of monitoring for patients recommended for operation varied from 1 to 10 years. The control group consisted of 31 patients (15 males and $16 \mathrm{fe}-$ males) with a mean age of 68.5 years (range, $24-89$ years). Patients with IBD-associated cancer were not included in the control group. Additionally, neither group received bowel preparations with oral antibiotics. Resection of the terminal ileum and caecum followed by a right-sided colectomy was performed using a laparoscopy approach. In cases of limited space and diminished transparency, open laparotomy was performed. At the time of resection, tissue specimens were taken from the outer portion of the terminal ileum wall and adjacent mesenterium in both of groups. All preoperative samples from $\mathrm{CD}$ patients positive for $C$. albicans were obtained from either the outer portion of the bowel wall or the adjacent mesenterium not from the lumen of the bowel. In the control group of 31 patients with malignancy, the samples were obtained during surgery under the same conditions and originated from the same outer wall of the bowel and the adjacent mesenterium. The specimens were placed into test tubes filled with $10 \%$ glucose under sterile conditions and were immediately sent for microbiological evaluation. Sabouraud-gentamicin-

Table 1. Cohort of patients

\begin{tabular}{lcccc}
\hline Variable & $\begin{array}{c}\text { Crohn disease } \\
(\mathrm{n}=54)\end{array}$ & $\begin{array}{c}\text { Control group } \\
(\mathrm{n}=31)\end{array}$ & $\chi^{2}$ & P-value \\
\hline Sex & $34(63.0)$ & $15(48.4)$ & & \\
$\quad$ Male & $20(37.0)$ & $16(51.6)$ & & \\
$\quad$ Female & 35.4 & 68.5 & & \\
Average age (yr) & 34.8 & - & & \\
$\quad$ Male & 36.8 & - & \\
$\quad$ Female & $32(59.3)$ & $0(0)$ & & \\
Immunosuppressive & & & & \\
$\quad$ treatment & $10(62.5)$ & - & \\
Immunosuppressive \\
treatment (16 patients \\
$\quad$ with positive cultivation)
\end{tabular}

Values are presented as number (\%) unless otherwise indicated. chloramfenicol 2 agar (SGC2) (bioMérieux, Chemin de l'Orme, France) and chromID Candida agar (CAN2) (bioMérieux, Chemin de l'Orme, France) were used to cultivate fungi for 3-5 days in a thermostat (Binder-Merck Inc., Philadelphia, PA, USA) at $37^{\circ} \mathrm{C}$. The first evaluation was done after 48 hours, and the second evaluation was performed 10 days after collection of the specimens. When the cultivation was complete, the phyla were identified using a MALDI-TOF MS biotyper (Bruker Daltonics Inc., Billerica, MA, USA). Postsurgical treatment of patients with positive cultures for Candida and yeasts was not included in our study.

The surgeries performed were part of a standard course of treatment, and written consent was obtained from all patients who underwent this procedure. The ethics committee of the Hospital Košice-Šaca, Ltd., 1st Private Hospital, Košice-Šaca approved this study. Additionally, in our hospital we reduce all possible causes of infection through active monitoring.

Mean values with one standard deviation were computed for the relevant data. Comparisons were calculated using Pearson chisquare test, and P-values $<0.05$ were considered significant. All statistical analyses were performed using IBM SPSS Statistics ver. 22.0 (IBM Co., Armonk, NY, USA).

\section{RESULTS}

The inflamed mucosa showed typical inflammatory changes in all CD patients. Fungal infections were found in the tissues obtained from the peritoneal cavity of $16 \mathrm{CD}$ patients (29.6\%). C. albicans was identified in 12 patients (75\%), and yeasts were present in 4 patients (25\%) (Table 2). Other types of fungi and yeast were not identified. Additionally, C. albicans was identified in 10 patients from the short-term cultivation. Furthermore, in 4 cases the shortterm cultivation and the long-term cultivation were positive for $C$. albicans. The presence of yeasts and C. albicans in preoperative samples was simultaneously confirmed on both types of culture media (SGC2 and CAN2). The average age of patients positive for C. albicans and yeasts was 31 years. Of the 16 patients with $\mathrm{CD}$

Table 2. Cultivation results

\begin{tabular}{lcccc}
\hline Variable & $\begin{array}{c}\text { Crohn disease } \\
(\mathrm{n}=54)\end{array}$ & $\begin{array}{c}\text { Control group } \\
(\mathrm{n}=31)\end{array}$ & $\chi^{2}$ & P-value \\
\hline Positive cultivation & $16(29.6)$ & $2(6.45)$ & 6.338 & 0.012 \\
Candida albicans & $12(75.0)$ & $2(100)$ & 3.560 & 0.059 \\
$\quad$ Short-term cultivation & 10 & 2 & 2.365 & 0.124 \\
Long-term cultivation & 12 & 2 & 3.560 & 0.059 \\
Yeasts & $4(25.0)$ & $0(0)$ & NA & \\
Short-term cultivation & 4 & 0 & NA & \\
Long-term cultivation & 4 & 0 & NA & \\
\hline
\end{tabular}

Values are presented as number (\%) unless otherwise indicated. NA, not applicable. 
Table 3. Surgery types

\begin{tabular}{lcccc}
\hline Surgery type & $\begin{array}{c}\text { Crohn disease } \\
(\mathrm{n}=54)\end{array}$ & $\begin{array}{c}\text { Control group } \\
(\mathrm{n}=31)\end{array}$ & $\chi^{2}$ & P-value \\
\hline $\begin{array}{l}\text { Terminal ileum and } \\
\text { caecum resection }\end{array}$ & & & & \\
Laparotomy & $14(25.9)$ & - & $\mathrm{NA}$ & \\
Conversion & $7(12.9)$ & - & $\mathrm{NA}$ & \\
Laparoscopy & $10(18.5)$ & - & $\mathrm{NA}$ & \\
SILS & $14(25.9)$ & - & $\mathrm{NA}$ & \\
Right-sided colectomy & & & & \\
Laparotomy & $6(11)$ & $14(45.2)$ & 12.69 & 0.0003 \\
Laparoscopy & $3(5.5)$ & $17(54.8)$ & 26.584 & 0.0000001 \\
SILS & $0(0)$ & $0(0)$ & & \\
\hline
\end{tabular}

Values are presented as number (\%) unless otherwise indicated.

SILS, single incision laparoscopic surgery; NA, not applicable.

who were positive for fungi and yeasts, 10 patients (62.5\%) had received immunosuppressive treatment before surgery. Imidazole was administered to a total of 18 patients, but only 5 of those patients were positive for C. albicans or yeasts. Infliximab (IFX) was used in 3 patients before surgery, none of whom were positive for C. albicans or yeasts. Inflammatory markers (e.g., leukocytosis and C-reactive protein) were elevated in 24 patients (44.4\%) with CD. In the group with $\mathrm{CD}$, drug allergy was present in 12 patients $(22.2 \%)$, food intolerance in 5 patients $(9.2 \%)$, and extraintestinal symptoms in 2 patients (3.7\%) (Table 1). In the control group of 31 patients, the presence of fungi and yeasts was confirmed in only 2 cases (6.45\%) (Table 2). The presence of $C$. albicans in tissue specimens was confirmed using short-term cultivation as well as cultivation in both culture media. Of the patients with $\mathrm{CD}$, resection of the terminal ileum and caecum was performed via laparotomy in 21 cases, laparoscopic resection in 10 patients, and singleincision laparoscopic surgery (SILS) in 14 patients. Right hemicolectomy was performed in 6 cases using laparotomy and in 3 patients using a laparoscopic procedure, but SILS was not used for the right hemicolectomy in either group. In 7 cases, the need to need to change from laparoscopy to laparotomy was due to limited space and diminished transparency. In the control group of patients with a malignancy, we resected the tumor on the right side, eventually extending to a colectomy, using laparotomy in 14 cases and laparoscopy in 17 cases. In that group, there was no need to convert the laparoscopy to laparotomy midsurgery (Table 3 ). In patients of both of group positive for fungal infection, the terminal ileum and caecum were resected using laparotomy in 5 patients, laparoscopy in 3 cases, and SILS resection in 4 cases. In 3 cases a conversion from laparoscopy or SILS to laparotomy was necessary. In cases where only right-sided colectomy was performed, only one patient was positive for fungal cultivation. Using Pearson chisquare test, patients with $\mathrm{CD}$ had significantly higher prevalence of fungi and yeast compared with cancer patients $\left(\chi^{2}=4.3873, \mathrm{P}<\right.$
Table 4. Statistical analysis of fungi- and yeast-positivity

\begin{tabular}{lccc}
\hline Group & $\begin{array}{c}\text { Candida-negative } \\
(\mathrm{n}=85)\end{array}$ & $\begin{array}{c}\text { Candida-positive } \\
(\mathrm{n}=18)\end{array}$ & $\begin{array}{c}\text { Total } \\
(\mathrm{n}=103)\end{array}$ \\
\hline Crohn disease & $54(57.77 \%)$ & $16(12.23 \%)$ & $70(100 \%)$ \\
Cancer & $31(27.23 \%)$ & $2(5.77 \%)$ & $33(100 \%)$ \\
\hline
\end{tabular}

The chi-square value is 4.3873 . The P-value is 0.036 . This result is significant at $\mathrm{P}<0.05$.

0.05) (Table 4). There were no differences between the surgical approaches in terms of positive cultivation of fungi and yeasts.

\section{DISCUSSION}

A number of prospective observational studies and case reports have been published highlighting the predisposition of patients with IBD for the development of severe infections due to opportunistic and common microbial pathogens [6,7]. Opportunistic infections are infections caused by microorganisms invading a weakened immune system. In cases of immunocompetent hosts, the disease is typically mild or not apparent [8]. Opportunistic infections often are associated with significant morbidity and mortality and may be difficult to treat effectively [9]. Opportunistic infections are common in patients with CD and colitis ulcerosa and have been described previously in retrospective case reports, case series [7, 10-14], and prospective clinical trials of new therapies for IBD [15-17]. In our study, bowel perforation and abscess did not occur before surgery. Instead, the patients were scheduled for routine surgery, and it was difficult to retrospectively correlate the development of fistulae with intra-abdominal fungal infections. The European Crohn's and Colitis Organisation states that all patients with IBD on corticosteroids, immunomodulators, or biological agents should be considered as immunocompromised and at risk for opportunistic infections [18]. Of the 3 patients treated with IFX, none were positive for yeasts or C. albicans and treatment with imidazole was not followed increased occurrence of fungi infections. Of the 18 patients treated with imidazole, only 5 were positive for C. albicans or yeasts (27\%). The risk factors and outcomes of opportunistic infections in IBD patients have not been well evaluated. Nonetheless, neutropenia is considered a predisposing factor for opportunistic infection with bacterial opportunists such as Pseudomonas aeruginosa and opportunistic fungi such as Candida and Aspergillus. Although there were no patients with neutropenia or fever in either group in this study, the identification of IBD patients at risk for serious opportunistic infections is important to optimize patient outcomes through the development of prophylactic or preemptive strategies [8]. However, despite the fact that specific drugs, including corticosteroids, AZA/6MP, and IFX, are associated with specific opportunistic infections, many of these infections were also present in patients not taking those specific drugs [8]. CD patients are more frequently and more heavily colonized by $C$. albicans than healthy subjects 
[19], and anti-Saccharomyces cerevisiae antibodies are present in $50 \%-60 \%$ of CD patients [20]. Invasive Candida infections are primarily caused by 4 species: C. albicans, Candida glabrata, Candida parapsilosis, and Candida tropicalis [21]; however, only C. albicans was found in this study. Immunosuppression in IBD is associated with oral, oesophageal, or systemic candidiasis, although there is currently no specific recommendation for screening or prophylaxis [18]. In 2009, the TREAT (The Crohn's Therapy, Resource, Evaulation and Assessement Tool) registry reported 4 cases of systemic candidiasis, diagnosed from cultures of blood or the affected site [18, 21], in patients with CD over a 5-year followup, of which 3 patients were treated with infliximab and 1 was treated with an immunomodulator. In contrast, IFX use in the preoperative period was not associated with an increase in total, infectious, or noninfectious complications in 734 patients with UC undergoing abdominal surgery according to a long-term follow-up study by Fidder et al. [22]. However, for the IFX-treated patients presenting with infections, corticosteroid treatment was an independent risk factor. In our study, there was a significantly higher rate of extraintestinal Candida infections in comparison with the control group of cancer patients. Stress-induced increased intestinal permeability may occur in healthy controls as well as in IBD patients [23-27] and can be seen in other chronic inflammatory disorders like asthma and coeliac disease $[28,29]$. While the inflamed ileal mucosa from patients with CD did not differ from those of the control group with colonic cancer, inflamed specimens typically show significantly increased permeability [30]. In this study, we found a significant difference in the cultivation rates from abdominal cavity of $\mathrm{CD}$ patients compared to the control group of patients with cancer. This suggests that patients with IBD may be at a higher risk for opportunistic infections, which is significantly increased when patients take immunosuppressants [8]. However, it is important to determine whether Candida infection causes or is a consequence of a chronic course. Although no complications occurred in connection with sampling for cultivation, we have interrupted our research so that we can fully evaluate the results to date, and we plan to continue this research in the future.

In conclusion, the patients with IBD may be at risk of opportunistic infections that can substantially influence mortality and morbidity. Our study showed a significantly higher rate of extraintestinal, but not intraluminal, Candida infections in the abdominal cavity of $\mathrm{CD}$ patients compared to the control group of patients with colon cancer at the time of surgery. However, there is a need for further evaluation of the role of fungal infections in CD and their influence on course of this entity.

\section{CONFLICT OF INTEREST}

No potential conflict of interest relevant to this article was reported.

\section{ACKNOWLEDGMENTS}

We are grateful for the statistical analysis provided by Peter Kolarčik, who participated in this work without any financial interest.

\section{REFERENCES}

1. Rutgeerts P, Goboes K, Peeters M, Hiele M, Penninckx F, Aerts R, et al. Effect of faecal stream diversion on recurrence of Crohn's disease in the neoterminal ileum. Lancet 1991;338:771-4.

2. Sartor RB. Microbial influences in inflammatory bowel diseases. Gastroenterology 2008;134:577-94.

3. Seksik P, Sokol H, Lepage P, Vasquez N, Manichanh C, Mangin I, et al. Review article: the role of bacteria in onset and perpetuation of inflammatory bowel disease. Aliment Pharmacol Ther 2006;24 Suppl 3:11-8.

4. Majid Z, Mahmoudabadi AZ. Invasive candidiasis; a review article. Jundishapur J Microbiol 2009;2:1-6.

5. Liuchang HC, Hsu TC. Surgical and nutritional intervention of Crohn's disease. J Soc Colon Rectal Surgeon (Taiwan) 2008;19:20-5.

6. Azie N, Neofytos D, Pfaller M, Meier-Kriesche HU, Quan SP, Horn D. The PATH (Prospective Antifungal Therapy) Alliance ${ }^{\mathbb{B}}$ registry and invasive fungal infections: update 2012. Diagn Microbiol Infect Dis 2012;73:293-300.

7. Lichtenstein GR, Feagan BG, Cohen RD, Salzberg BA, Diamond $\mathrm{RH}$, Price S, et al. Serious infection and mortality in patients with Crohn's disease: more than 5 years of follow-up in the TREAT ${ }^{\text {TM }}$ registry. Am J Gastroenterol 2012;107:1409-22.

8. Toruner M, Loftus EV Jr, Harmsen WS, Zinsmeister AR, Orenstein R, Sandborn WJ, et al. Risk factors for opportunistic infections in patients with inflammatory bowel disease. Gastroenterology 2008;134:929-36.

9. Klein NC, Go CH, Cunha BA. Infections associated with steroid use. Infect Dis Clin North Am 2001;15:423-32, viii.

10. Arts J, D'Haens G, Zeegers M, Van Assche G, Hiele M, D'Hoore A, et al. Long-term outcome of treatment with intravenous cyclosporin in patients with severe ulcerative colitis. Inflamm Bowel Dis 2004;10:73-8.

11. Colombel JF, Loftus EV Jr, Tremaine WJ, Egan LJ, Harmsen WS, Schleck CD, et al. The safety profile of infliximab in patients with Crohn's disease: the Mayo clinic experience in 500 patients. Gastroenterology 2004;126:19-31.

12. Hamlin PJ, Shah MN, Scott N, Wyatt JI, Howdle PD. Systemic cytomegalovirus infection complicating ulcerative colitis: a case report and review of the literature. Postgrad Med J 2004;80:233-5.

13. Jess T, Winther KV, Munkholm P, Langholz E, Binder V. Mortality and causes of death in Crohn's disease: follow-up of a population-based cohort in Copenhagen County, Denmark. Gastroenterology 2002;122:1808-14.

14. Winther KV, Jess T, Langholz E, Munkholm P, Binder V. Survival and cause-specific mortality in ulcerative colitis: follow-up of a 
population-based cohort in Copenhagen County. Gastroenterology 2003;125:1576-82.

15. Hanauer SB, Feagan BG, Lichtenstein GR, Mayer LF, Schreiber S, Colombel JF, et al. Maintenance infliximab for Crohn's disease: the ACCENT I randomised trial. Lancet 2002;359:1541-9.

16. Hanauer SB, Sandborn WJ, Rutgeerts P, Fedorak RN, Lukas M, MacIntosh D, et al. Human anti-tumor necrosis factor monoclonal antibody (adalimumab) in Crohn's disease: the CLASSIC-I trial. Gastroenterology 2006;130:323-33.

17. Colombel JF, Sandborn WJ, Rutgeerts P, Enns R, Hanauer SB, Panaccione R, et al. Adalimumab for maintenance of clinical response and remission in patients with Crohn's disease: the CHARM trial. Gastroenterology 2007;132:52-65.

18. Rahier JF, Ben-Horin S, Chowers Y, Conlon C, De Munter P, D'Haens G, et al. European evidence-based Consensus on the prevention, diagnosis and management of opportunistic infections in inflammatory bowel disease. J Crohns Colitis 2009;3:4791.

19. Standaert-Vitse A, Sendid B, Joossens M, François N, Vandewalle-El Khoury P, Branche J, et al. Candida albicans colonization and ASCA in familial Crohn's disease. Am J Gastroenterol 2009; 104:1745-53.

20. Quinton JF, Sendid B, Reumaux D, Duthilleul P, Cortot A, Grandbastien B, et al. Anti-Saccharomyces cerevisiae mannan antibodies combined with antineutrophil cytoplasmic autoantibodies in inflammatory bowel disease: prevalence and diagnostic role. Gut 1998;42:788-91.

21. Ahmad S, Khan Z. Invasive candidiasis: a review of nonculturebased laboratory diagnostic methods. Indian J Med Microbiol 2012;30:264-9.
22. Fidder H, Schnitzler F, Ferrante M, Noman M, Katsanos K, Segaert S, et al. Long-term safety of infliximab for the treatment of inflammatory bowel disease: a single-centre cohort study. Gut 2009;58:501-8.

23. Lewis K, Caldwell J, Phan V, Prescott D, Nazli A, Wang A, et al. Decreased epithelial barrier function evoked by exposure to metabolic stress and nonpathogenic E. coli is enhanced by TNF-alpha. Am J Physiol Gastrointest Liver Physiol 2008;294:G669-78.

24. Nazli A, Yang PC, Jury J, Howe K, Watson JL, Söderholm JD, et al. Epithelia under metabolic stress perceive commensal bacteria as a threat. Am J Pathol 2004;164:947-57.

25. Yang PC, Jury J, Söderholm JD, Sherman PM, McKay DM, Perdue $\mathrm{MH}$. Chronic psychological stress in rats induces intestinal sensitization to luminal antigens. Am J Pathol 2006;168:104-14.

26. Meddings JB, Swain MG. Environmental stress-induced gastrointestinal permeability is mediated by endogenous glucocorticoids in the rat. Gastroenterology 2000;119:1019-28.

27. Wallon C, Yang PC, Keita AV, Ericson AC, McKay DM, Sherman $\mathrm{PM}$, et al. Corticotropin-releasing hormone (CRH) regulates macromolecular permeability via mast cells in normal human colonic biopsies in vitro. Gut 2008;57:50-8.

28. Arrieta MC, Bistritz L, Meddings JB. Alterations in intestinal permeability. Gut 2006;55:1512-20.

29. Benard A, Desreumeaux P, Huglo D, Hoorelbeke A, Tonnel AB, Wallaert B. Increased intestinal permeability in bronchial asthma. J Allergy Clin Immunol 1996;97:1173-8.

30. Söderholm JD, Olaison G, Peterson KH, Franzén LE, Lindmark T, Wirén $\mathrm{M}$, et al. Augmented increase in tight junction permeability by luminal stimuli in the non-inflamed ileum of Crohn's disease. Gut 2002;50:307-13. 